\title{
Challenges to Geophysical Ecosystems and Proposals for Improvement
}

\section{Jonah Lissner*}

Independent Researcher, Lissnerresearch.weebly.com, USA

\begin{abstract}
Interdisciplinary approaches to human-caused environmental degradation have a global effect. Problems and potential solutions are addressed in scientific disciplines ecology, geoastronomy, and medical technology from space technology engineering, research and development.
\end{abstract}

\section{Introduction}

The main problems of unnatural or extra-natural pollution effects on specific ecosystem regions on planet earth include potential degradation of air atmosphere and ozone layer [1] by chemical pollutants including chlorofluorocarbons, soil quality and proper generation of soil and topsoil [2], control and management of the hydrologic cycle, disposal of wastes, and recycling of nutrients [3]. In general the pace of these changes of removal, degradation and improper replacement of the air, soil and water problems has generated worsening natural qualities for entirety of planetary use.

\section{Specific Problems to be Addressed: Air, Soil and Water Erosion and Human Effects and Environmental Applications of Space Technology}

The effect of humans on quality of the atmosphere, generation of soils, control of the hydrologic cycle, disposal of wastes, and recycling of nutrients in farming practices are proposed to be of high importance. How are these aspects controlled by natural ecosystems mechanics, and how have humans impacted that control?

Due to technology and energy manufacture requiring rare materials and solvents, overpopulation of given areas near waterways, air, soil, noise, energy and water pollution, over farming or incorrect farming practices [4], overfishing of natural fresh and sea-waters [5], burning of fossil fuels, and other harmful practices, humans have cause the ozone layer and natural air, soil and water balance in each given ecosystem, to erode over time, leaving weaker and polluted natural cycles in their place, in each given region.

Loss of arable soil, further negative impact by the hydrologic cycle through pollution, damming and overuse, landfills and sewage treatment facilities in a given region, where land, water and air are at a premium for continuous human usage. Potential costs include refrigerant production, industrial solvent and oil pollution, waste disposal and water system usage inefficiencies. Medical technology for testing of environmental reasons for infertility and ultrasound amniocentesis aid in the conception and gestation of life, while geospatial imaging, xray, magnetic resonance imaging, chemotherapy, and dialysis are technologies that have evolved from space technology and testing and the global perspective.

Superhighways and greater urban congestion using greater amounts of fossil fuels and treated waters are one measure result of human material success and ecological ramifications that can be measured from space; greater usage of energy and space, require greater custodial ship and managerial ability of each human society within their environmental space, to think as a planetary network.

\section{Air pollution}

Challenge: The addition of CFCs used in human products for industrial use [6] and application has eroded the ozone layer, resulting in increased levels of ultraviolet radiation in the earth's atmosphere and increased risk for skin, nervous and respiratory disease. These dire effects on realistic biospheric health levels were recognized by the Montreal Protocol beginning in 1987 [7].

Proposed solution: Reduction of CFC in usage of solar, water, magnetic and plasma systems for induced power generation and transmission for manufacturing and transportation utilization.

\section{Soil pollution}

Challenge: Increase in human population needs for rapid farming and high-yield crop generation [2] using inexpensive initial cost fertilizer and pesticides has resulted in lessening topsoil and increase in polluted groundwater. To exaggerate the problem, a rapid increase in human population has resulted in a high increase in sewage and water pollution from contaminants and sedimentation, using up resources, space and energy for increased treatment and storage across the water table and arable land in said regions $[8,9]$.

Proposed solution: Utilization of sustainable, low-impact farming techniques including aquaculture, native grass and vermin predator introduction, controlled greenhouses, drip-irrigation methods, and organic farming methodologies to reduce need for over-Nitrogenated topsoil usage and elimination of unnecessary GMO crops.

\section{Water pollution}

Challenge: Acidic rain [10] a is a result of higher levels of water and soil $\mathrm{Ph}$-acidity, in rainfall, altering biomass including forest, geological strata, soil and water quality across regions of human, animal and plant inhabitation [11]. Additionally, human activity such as damming and over-gentrification has caused major coastal areas to erode at a faster rate and sink at a faster rate from rising global water levels due to global warming problems from solar emissions, decreased ozone layer, and human air pollution, melting the planetary polar ice caps.

*Corresponding author: Jonah Lissner, Ph.D, Independent Researcher, USA Tel: +058-142-758-828; Fax: +059-160-066-147; E-mail: Scitek1@mail.com

Received October 13, 2014; Accepted October 25, 2014; Published October 28 2014

Citation: Lissner J (2014) Challenges to Geophysical Ecosystems and Proposals for Improvement. J Geophys Remote Sensing 3: 133. doi:10.4172/21690049.1000133

Copyright: (ㅇ 2014 Lissner J. This is an open-access article distributed under the terms of the Creative Commons Attribution License, which permits unrestricted use, distribution, and reproduction in any medium, provided the original author and source are credited. 
Proposed solution: Reduction of SO_2 and $\mathrm{NO} \_x_{\text {emissions from }}$ manufacturing centers and transportation highways and urban regions by utilizing electric or hydrogen-cell vehicles; selective drilling for aquifers and underground water; water-generation machines; landrebuilding to maximize coastal and island regions for greater managed land development.

\section{Ecosystem Improvement Heuristics and Methodologies}

Challenge: Diagnosing, analysing, and methods to engineer repair solutions to problems to increase human public health and ecosystem health are required.

Proposed solution: One method is an increase in innovation of ecosystem clean-up, renewal and change of industrial practice for future healthy development. Another method for global regional ecosystem improvement is medical applications from geophysics, distributed systems and orbital space technology [12]. Disease, disability and the quest for more stable health practices have required evolving technologies using a global and holistic approach to solve regionally, ecosystem and human health problems in any given society. Leading causes of natural death, such as heart disease and cancer, and medical and health practices to improve health, such as elimination of tobacco smoke inhalation and pesticides in foods, are showing improvements in these goals [13].

\section{Summary}

Introducing new medical technologies can affect the patients initially receiving the treatments, because effects may not be entirely clear. By extending life expectancy, human societies risk greater overpopulation. New technologies are available to those who have money or insurance, where in less-affluent societies these opportunities are less available. Furthermore, development of medical technologies requires investment in time, resources, capital, and experimentation.

However, humankind as a whole has widely benefitted from advancements in medical technology, with reduced infant mortality, extended life expectancies, and greater quality of life. This allows human societies to decide how healthy they wish to be, with obvious beneficial or detrimental effects, if overuse, overconsumption, or over pollution of given areas are not addressed.

\section{References}

1. http://ozonewatch.gsfc.nasa.gov/monthly/monthly_1996-10_SH.html.

2. http://www.sciencedirect.com/science/article/pii/0167198795010033.

3. http://www.fao.org/docrep/W2598E/W2598E00.htm.

4. http://archive.unu.edu/unupress/unupbooks/uu22we/uu22we0c.htm.

5. http://www.seaweb.org/resources/citations/fisheries/1996/96overfishing.3.php.

6. http://www.sciencedirect.com/science/article/pii/S0378517300004014.

7. http://en.wikipedia.org/wiki/Montreal_Protocol.

8. http://iels.intnet.mu/water_mau.htm.

9. http://www.who.int/water_sanitation_health/resourcesquality/wqmchap10.pdf.

10. http://en.wikipedia.org/wiki/Acid_rain.

11. http://www.epa.gov/airtrends/aqtrnd96/brochure/acidrain.html.

12. http://spinoff.nasa.gov/spinoff1996/12.html.

13. http://www.allcountries.org/uscensus/129_death_and_death_rates_by_age. html. 